\title{
O que é ser antropólogo hoje
}

PAULA MONTERO

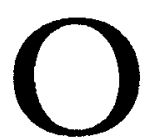

Departamento de Antropologia da Faculdade de Filosofia, Letras e Ciências Humanas, surgiu de um desmembramento do antigo Departamento de Ciências Sociais. Essa sua especificidade faz com que não exista, em nível de graduaçăo, a carreira de antropólogo. A formaçáo básica do aluno se realiza, no interior do curso de Ciências Sociais. Somente em nível de pós-graduação o futuro profissional terá um treinamento acadêmico e de pesquisa mais especializado. Vejamos de maneira sucinta no que ele consiste.

\section{A Antropologia no curso de Ciências Sociais}

O aluno que escolhe essa formaçáo terá em seu currículo uma distribuição equilibrada de cursos em três áreas principais: Sociologia, Antropologia e Ciência Política. Em cada uma delas deverá cursar quatro disciplinas obrigatórias e um número variável de optativas segundo se oriente preferencialmente para um outro desses campos.

O Departamento de Antropologia, talvez mais do que outros que integram o curso de Ciências Sociais, tem respondido aos desafios que o ensino de graduação oferece, pela busca de uma integração da pesquisa ao ensino de graduação, dado o papel crucial que ela desempenha na produção do conhecimento antropológico. Essa preocupaçăo é concretizada basicamente através de três caminhos:

- agregação informal de alunos em torno de professores formando pequenos núcleos de pesquisa que reúnem alunos de pós-graduação e alunos de graduação cursando cadeiras optativas. Essa troca de experiência de trabalho de campo e de reflexão teórica entre estudantes com diferentes níveis de formaçáo contribui para o enriquecimento do trabalho intelectual, permitindo rápido amadurecimento;

- investimento sistemático no treinamento de alunos em trabalho de campo. Esta prioridade gerou uma prática de acompanhamento de alunos de graduação em viagens ao campo de pesquisa. Tanto na área de etnologia indígena e antropologia rural, quanto na de estudos urbanos, essa orientaçáo vem sendo institucionalizada pelo Departamento como parte das atividades de ensino de graduação; 
- implantaçáo do Programa Especial de Treinamento (PET) com o apoio da Capes. O Programa visa fornecer a alunos de comprovada excelência acadêmica uma formação especial, centrando-se, porém, ao contrário do que ocorre no currículo normal da graduaçáo, que parte da teoria para a prática, na diversidade de seus interesses. Esses alunos-bolsistas são integrados aos projetos de pesquisa em andamento nos três departamentos que integram o curso, recebendo, a partir daí, formação teórica homogênea $\mathrm{e}$ aprofundada nas três áreas. $\mathrm{O}$ projeto PET visa, assim, a funcionar como um pólo de agregaçáo de todas as atividades de integração da pesquisa ao ensino de graduação, que, até agora, vinham sendo desenvolvidas de forma pouco sistemática, através de iniciação científica, grupos de estudo etc. Desse modo, esperase racionalizar o investimento do trabalho docente na orientaçáo dos alunos da graduação, permitindo conferir-lhe maior coerência e organicidade. Além disso, por essa via busca-se ampliar a formaçăo teórica do cientista social, hoje tendendo rapidamente para uma especialização prematura, ainda que se conserve uma base de trabalho de pesquisa específica em uma das áreas do curso.

\section{Perfil do corpo discente}

Embora não se disponha de dados atualizados sobre o perfil do corpo discente no curso de Ciências Sociais, a experiência docente tem demonstrado que algumas de suas caraterísticas, detectadas por pesquisa da década de 80, parecem não ter sofrido alteraçóes significativas.

O que a experiência parece confirmar é que o corpo discente, composto aproximadamente por mil alunos regularmente inscritos e distribuídos em dois períodos - vespertino e noturno - , constitui um grupo relativamente heterogêneo, formado, grosso modo, por dois principais segmentos. O primeiro, constituído por jovens recém-saídos do curso secundário, egressos em geral de colégios particulares e que se concentram basicamente no período vespertino. O segundo é formado sobretudo por alunos, em sua maioria do sexo masculino, oriundos de famílias com nível de escolaridade mais baixo, e que freqüentam o curso após a jornada diária de trabalho em tempo integral. Destes, número considerável já possui diplomas universitários ou freqüenta outro curso paralelamente ao de Ciências Sociais. Ainda que seja possível aproximá-los pelo fato de, em sua maioria, os alunos dos dois períodos provirem de estratos sociais médios mais favorecidos, muito embora se tenham atenuado nos últimos anos as diferenças que separam de modo nítido os dois segmentos, persistem no entanto, os traços que caracterizam de maneira distinta o perfil dos estudantes dos cursos vespertinos e noturno. 
Em função desta diversidade, o estudante de Ciências Sociais oscila entre a preocupação com a realidade brasileira e a vaga inquietação política de um lado, e, de outro, uma imprecisa e difusa preocupaçáo com a carreira profissional, nem sempre relacionada com o curso. Uma vez que muitos já possuem um diploma em outro curso superior, tendem a ver $o$ estudo das Ciências Sociais como forma de extensão cultural e de ampliaçăo de horizontes.

Os que tomam as Ciências Sociais e, em especial, a Antropologia como um caminho profissionalizante tendem a encaminhar-se para a pós-graduaçáo, como passo para uma carreira científica ou universitária, ou para o campo do planejamento (habitualmente em órgãos estatais), de pesquisa de mercado ou de atividades em Organizaçōes não Governamentais (ONGs).

Assim, talvez fosse mais apropriado falar não em um, mas em diversos perfis profissionais que caracterizam as atividades do profissional oriundo do curso de Ciências Sociais. Talvez exatamente nessa flexibilidade, derivada da diversidade, resida o maior triunfo do estudante frente às exigências sempre moventes do mercado de trabalho.

\section{As atividades de extensão universitária}

Por muitas razóes que seria difícil trazer aqui, a Antropologia tem exercido, nas últimas duas décadas, papel de especial destaque na sua contribuição para a reflexão dos problemas que afligem a sociedade brasileira. Os docentes do Departamento têm se destacado por sua participação nos grandes debates nacionais, colaborando na definição de políticas públicas, como no caso da participação de professores no levantamento e diagnóstico das universidades brasileiras; assessorando o Congresso Nacional, o Judiciário, o Executivo, como fizeram os etnólogos à época da elaboração da nova Constituição, na definição dos capítulos referentes aos direitos indígenas ou, mais recentemente, na proposição de emendas ao projeto da nova Lei de Diretrizes e Bases em tramitaçáo no Congresso Nacional.

No tocante à questáo fundiária e à defesa dos direitos de minorias no país, membros do Departamento de Antropologia têm sido convocados a assessorar o Ministério Público, seja participando em simpósios interdisciplinares, seja atuando como especialistas em perícias técnicas.

No que se refere ao aproveitamento das oportunidades de integração da pesquisa ao ensino através de extensão, o Departamento conta atualmente com dois projetos. Um deles, Quando o espelho naio reflete estudo sobre a formagáno da identidade de portadores de deficiencia na USP, 
faz parte do programam Reintegra desenvolvido pela Cecae e vem sendo realizado graças às bolsas de iniciaçăo, patrocinadas pela própria próreitoria. O outro, Perus - desenterrando a nossa historia, destina-se a produzir material didático para os alunos do segundo grau da rede oficial do estado, sobre os anos de repressáo durante os governos militares. Essa equipe acompanhou $o$ andamento das atividades resultantes da descoberta das ossadas de presos políticos desaparecidos numa vala clandestina do cemitério de Perus.

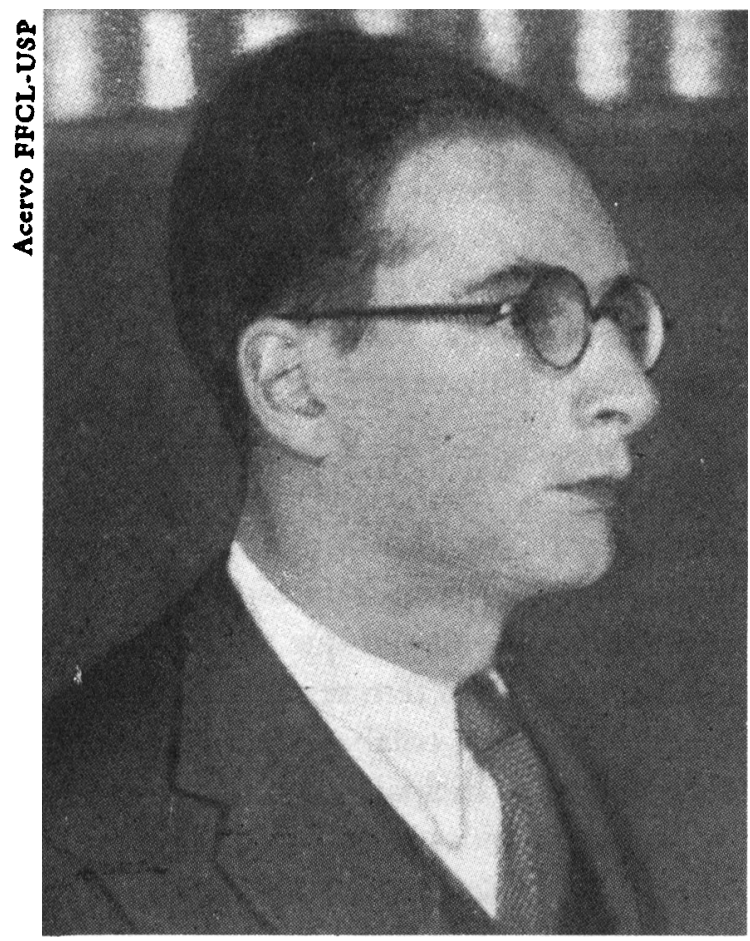

LEvi-Strauss

Ainda nessa linha de trabalho podemos destacar a participação de vários docentes em trabalhos de assessoria a movimentos sociais e a instituiçóes governamentais. Poderíamos lembrar aqui o trabalho do Centro MARI que se destina a produzir material pedagógico sobre as culturas indígenas para os currículos do segundo grau e a assessorar aqueles que se dedicam à educaçáo indígena na área. Finalmente, não poderíamos esquecer a atuação essencial de antropólogos no acompanhamento crítico de grandes projetos governamentais, como o complexo Carajás, com sério impacto sobre o meio ambiente e sobre populaçốes específicas em todo país. 
Vemos, portanto, que esse tipo de atuação, ao mesmo tempo que leva a sociedade brasileira à contribuiçăo crítica e competente de profissionais com sólida formaçáo acadêmica, coloca para a Antropologia novos desafios teóricos e metodológicos, serve de estímulo à própria reflexáo científica e, nesta medida, ao desenvolvimento da pesquisa social.

Além disso, não se pode esquecer que, para muitos alunos, a graduaçáo representa um curso terminal, já que contingente significativo dos que nele se inscrevem costuma vir de outras áreas, sobretudo das ciências exatas: Politécnica, Física, Matemática, Química etc., buscando o curso de Ciências Sociais, tal como o de Filosofia, como complementaçáo humanística à formaçáo excessivamente técnica de suas áreas de origem.

Tudo ressalta a importância e o valor das atividades de extensáo universitária como momento privilegiado que permitiria, ainda em nf́vel da graduaçáo, colocar o estudante em contato com a realidade frente à qual, num futuro próximo, será solicitado a demostrar seus conhecimentos: no mercado de trabalho.

\section{Pós-graduação e pesquisa na Antropologia}

O setor de pós-graduaçáo é um dos mais dinâmicos do Departamento. Conta hoje com aproximadamente cem alunos vindos das várias universidades do país. Tem desempenhado papel de particular importância na formaçáo e titulação de docentes em exercício na enorme rede das universidades federais.

As atividades de pesquisa do setor de pós-graduaçáo se desenvolvem atualmente em torno de três eixos temáticos fundamentais: a etnologia indígena, o estudo das populaçóes negras e o mundo da cultura nos grandes centro urbanos.

O setor de etnologia já é dono de uma vasta tradição de pesquisa. Desde os anos 50 consagrou-se ao estudo da vida e organizaçáo social dos grupos indígenas brasileiros, acumulando desde entâo longa experiência no conhecimento dessas sociedades e na formaçáo de etnólogos. No momento atual, problemas mobilizam os estudos em desenvolvimento nessa área: por um lado, a partir da renovaçáo das fontes documentais existentes sobre esses grupos, procura-se retraçar uma ampla história das sociedades indígenas bem como de suas relaçōes com a sociedade envolvente, em particular a legislaçáo e a ação indigenista; por outro lado, a atual reorganização dos movimentos indígenas leva à rediscussáo do problema da identidade étnica, e do lugar do xamanismo e das representaçóes mitológicas na sua construçăo. 
A questão do negro é hoje uma das mais cadentes, quando se procura pensar a construçáo da cidadania na sociedade brasileira. $O$ Departamento de Antropologia vem desenvolvendo pesquisas nessa área, marcadas fundamentalmente por dois eixos principais: o primeiro, que podemos chamar de africanista, procura compreender o processo colonial na África e o modo como se constituíam os Estados africanos independentes; o segundo eixo volta-se para as expressóes da cultura negra no Brasil, envolvendo tanto o estudo de grupos relativamente isolados e tradicionais quanto o de negros no contexto urbano, com sua organização política e suas manifestaçōes religiosas.

O mundo da cultura é o setor que congrega atualmente o maior número de pesquisadores. Fruto de demanda, que a complexidade e as transformaçōes recentes da vida nos grandes centros urbanos, torna cada vez mais premente, este campo de estudos é, por sua natureza, vasto e heterogêneo. Apesar da diversidade que congrega, uma mesma problemática caracteriza o perfil do setor. Trata-se de compreender os significados e os modos de operação das mais diversas manifestaçôes culturais, no momento em que a sociedade se apresenta como um conjunto fragmentado de vivências e crenças. Nesse sentido, interessa compreender o crescimento dos mais diversos tipos de religióes, o modo como a cidade abriga diferentes tipos de sociabilidade e finalmente, como as instituiçóes e seus intelectuais procuram pensar o Brasil enquanto nação.

\section{Laboratório de recursos visuais e sonoros}

Criado em 1990, o Laboratório de Recursos Visuais e Sonoros pretende abrir uma frente pioneira de pesquisa na Antropologia que incorpora som e imagem como instrumentos de investigação. Tem como objetivo, portanto, criar condiçóes adequadas que permitam a docentes, alunos e pesquisadores produzir e utilizar registros sonoros e visuais para suas pesquisas. Para tal dispomos de um laboratório fotográfico equipado e pretendemos, num futuro próximo, dispor de uma ilha de edição para material fílmico. Além de cursos de fotografia, voltados para a pesquisa antropológica e seminários de discussáo sobre Antropologia Visual, o Laboratório vem abrindo sua sala de vídeo para cursos que se utilizam de imagens. Ele já conta com um acervo de mil fotos em preto e branco, além de slides, negativos em vidro e chapas de impressão. são cerca de quatro mil imagens em diferentes tipos de suporte. Através de compras e doaçóes iniciamos nosso acervo de vídeo que conta hoje com mais de cinquienta fitas, cujos temas cobrem diferentes áreas de nossa disciplina.

Em associaçăo com esse acervo de imagens, alunos e professores 
já organizaram três exposiçōes fotográficas que procuram, via imagem, fazer uma reflexão sobre a maneira como o antropólogo olha para a realidade que analisa. A primeira delas, Nos bastidores da pesquisa de campo, que congregou imagens dos antropólogos em campo, procurou tornar visível a maneira como o antropólogo se relaciona com as populaçōes que estuda e como ele se auto-representa nessa relação. A segunda, Homens de Sciencia, retoma material iconográfico do século XIX, utilizado numa tese para mostrar como o problema das raças é equacionado pela Antropologia brasileira nascente. A terceira, $A$ vida cotidiana cm Changana, mostra a vida familiar de um grupo étnico de Angola, em plena guerra de independência.

\section{Publicações}

Todo esse processo de formação e de investigaçáo que descrevemos se expressa nas duas grandes publicaçóes do Departamento. A Revista de Antropologia e Cadernos de Campo. A Revista de Antropologia completou, neste ano, $\mathbf{4 0}$ anos de existência. Tem publicado a produçáo de pesquisadores nacionais e estrangeiros na área de Etnologia e Antropologia Social. Pretende ser um espaço de reflexão e debate das questóes mais atuais do campo. A Cadernos de Campo é uma iniciativa do corpo discente da pós-graduaçăo e está hoje em seu segundo número, publicação que procura congregar artigos relativos aos temas e preocupaçóes teóricas e metodológicas presentes nas teses e dissertaçóes do programa de pós-graduaçáo.

Este breve apanhado procurou delinear qual a natureza da formaçáo do antropólogo e qual a funçáo que ele desempenha na sociedade contemporânea.

Podemos perceber que a Antropologia se debate hoje com problemas sociais de enorme gravidade e que envolvem interesses muito poderosos. Sua capacidade de intervençáo dependerá, no entanto, da seriedade com que ela será capaz de pensar a si própria, seus instrumentos de cogniçáo e sua inserção, enquanto modo de conhecimento, na vida social.

Paula Montro é professoma do Departamento de Antropologia da Faculdade de Filosofia, Letras e Ciencias Humanas da USP. 